\title{
Why Social and Emotional Intelligence Matters in Workplace: An Evidence from a Developing Country
}

\author{
Rifat Afroze \\ Research and Evaluation Division, BRAC (NGO), Dhaka, Bangladesh
}

Copyright $\bigcirc 2016$ by authors, all rights reserved. Authors agree that this article remains permanently open access under the terms of the Creative Commons Attribution License 4.0 International License

\begin{abstract}
For ensuring maximum productivity at workplace, keen understanding on how emotion and social behavior affect performance, motivation, relationships, and confidence at work is essential. The social and emotional skills can underpin effective learning, positive behavior, and emotional health and well-being of those involved in work. Hence, BRAC (world leading non-government organization) decided to design a training programme that will cover the personnel's psychosocial needs. This competence also required in workplace for forming professional relationship, solving problems, and adapting with the complex situations at workplace. This study was undertaken to assess the social and emotional intelligence of BRAC staff. Data were collected from 174 randomly selected staff of BRAC head office (equally distributed by sex) through survey and group interviews. Young, mid and upper management staff were proportionately participated in data collection process. Findings reveal that staff understood their emotions and linking with them, seems motivated in their work, cooperate effectively with their peers. However, they felt a bit difficulty on regulating emotions like anger, tension and stress. Moreover, lack of confidence, nature to avoid disagreement and less relationship management skills (with supervisor) hampered their productivity. This study suggested introducing a training programme where some psychological and psychotherapeutic techniques and behavioral modeling would employ for enhancing social and emotional skills of BRAC staff.
\end{abstract}

Keywords Emotion, Self-awareness, Social Skills, Stress, Job Satisfaction

\section{Introduction}

For years it has been a lay belief that when we go for work we should leave our emotions at home. Not surprisingly, since it has long been thought that it is primarily people's intellect that determines the line of work they are in, their success and effectiveness and their overall competence both in their private and professional lives. Although this belief may certainly apply in some contexts, it should be viewed with caution. It may be true that certain Intelligence Quotient (IQ) levels are required for a person to get a certain job and maintain it. However, it has been shown that people who really stand out in their work are those who possess traits beyond intellect i.e. maturity, experience in dealing with people and situations, and that Goleman [1] has been called emotional health. Intelligence, on the other hand, refers to a person's ability to learn and remember information, to recognize concepts and their relations, and to apply the information in daily life in an adaptive way. In other words, it is a set of cognitive abilities that enable us to acquire knowledge for learning and solving problems. The importance of emotion in a person's daily dealings at the workplace is inevitably interrelated with his intellect.

Emotional Intelligence (EI) and Social and Emotional Intelligence (SEL)

The term EI has been coined in scientific literature to describe different things from simple mentions in psychotherapy treatment during the 1960s or as part of a multi-componential theory of intelligence [2]. It was Goleman [3], who popularized the term and offered a comprehensive account of the construct. EI, then, refers to "The ability to perceive and express emotion, assimilate emotion in thought, understand and reason with emotion, and regulate emotion in the self and others" (Mayer, et al. [4] ). It is a combination of cognition and affect, intelligence and emotion. EI enables to investigate how people can effectively use their emotional resource in their daily lives (Mount, et al. [5]). Before a decade the two theories Salovey and Mayer established that the SEI related with EI. Both concepts can identify the self-perceived ability, assess and control the emotion of a person or a group [4]. Starting by Thorndike, then Gardner and finally Bar-On, proposed a SEI model that consists of both intrapersonal and social competencies like able to recognize, understand and express emotions, regulate them, solve problems and generate positive affect and be self-motivated [2, 6-8]. Cherniss and Goleman [9], concludes that the SEI of the supervisor or peer 
will influence the potential of a relationship with that person for helping personnel develop and use the talent that is crucial for organizational effectiveness. In addition, employees with high SEI tend to be more satisfied with their job, better coping skills and ability to influence others.

\section{Methods and Materials}

In this study we calculate SEI in terms of personal and social competences in BRAC workplace. In addition explore whether there is any association between job satisfaction (JS) and SEI score of BRAC staff. Data were collected from 174 randomly selected head office staff through self-completed questionnaire and group interviews. They belonged to pay levels young to upper management from 34 departments. The Human Resource Division provided a list of 638 employees, 438 males and 200 females. They were divided into three groups: 228 in young, 297 in mid-management, and 113 in levels higher management by designation. Employees were selected randomly from each group. The selected employees were asked to read each question carefully and tick the appropriate box. Three employees sent blank questionnaires and three employees didn't provide background information. Thus, the sample size finally stood at 174. Furthermore, four group interviews (five employees in each) took place to gain insight on the personnel's overall experience of working at BRAC. The researcher rotated the questions to each person within the group, so that each of them could express their own opinion.

Table 1. Level and sex-wise employees in the survey

\begin{tabular}{|c|c|c|c|}
\hline Staff status & Male staff & Female staff & Total \\
\hline Young staff & 26 & 32 & 58 \\
\hline Mid-Manager & 28 & 31 & 59 \\
\hline Higher-Manager & 43 & 14 & 57 \\
\hline Total & 97 & 77 & 174 \\
\hline
\end{tabular}

The Instruments

A framework developed by The Consortium for Research on Emotional Intelligence was used in this study. This generic competency framework is derived, for the most part, from Working with Emotional Intelligence by Daniel Goleman [1]. In addition, job satisfaction of BRAC employees was also measured. For measuring job satisfaction we followed Smith, Kendall and Hulin's measurement techniques [10]. For measuring SEI, a five point Likert scale was used. Employees' perceptions by asking the extent to which they agree or disagree with a particular statement was measured. There are five competencies and each of them has several sub-components. Seventy-five sub-components are included in this framework. Researcher requested the participants to read each question carefully and tick to the appropriate box. Though Likert is a bipolar scaling method, here both the positive and negative modes were considered. Smith and other's index encompasses five main competencies with several sub-components. These are work, supervision, co-worker, pay and promotion. Both positive and negative mode statements were also used here. Group interviews were mainly focused on regulating emotions, several negative emotions like anger, stress, adjustment problems with peers were the key issues. Simultaneously, less answered topics were also discussed in interview session.

To check the reliability and validity a trial was also conducted where 14 colleagues were participated. After that an individual talking session also conducted separately. After that three important issues were uncovered. Some statements were ambiguous and some terms were unclear to the employees; and they felt hesitant to respond to some issues. Based on these some statements were re-phrased and some were excluded. Finally, 59 statements for SEI and 10 statements for JS were used. Furthermore, a brief introductory section which explained the purpose of the survey was included. For testing reliability, Cronbach's Alpha was 0.79 , which was quite acceptable. Additionally, reliability score of five sub scales of SEI also achieved quite satisfactory values, which were more than 0.6 .

\section{Findings}

Mean age of the employees was found nearly 41 years (male 42 and females around 35). Length of service was about 14 years for males and about 9 years for females. As expected, a positive relationship between age of the employees and level of employment within BRAC was observed.

\section{Awareness on Individual Emotions}

According to Goleman, self-awareness of emotion can be explained by recognizing own emotions and effects, knowing one's strengths and limitations and confidence about one's self-worth and capabilities [1]. Table 2 shows that employees suffered from anger, tension, stress, and felt less confident about their performance. Nearly $40 \%$ of the employees agreed that when they felt stressed they could not give quality output. This was confirmed by the participants of group discussions, where they expressed worry about fulfilling the demands of their job and meeting deadlines.

Additionally, ensuring the quality of their task also gives them strain. One staff stated that the modern life is full of hassles and frustrations which may stem from personal and family issues, but it affect professional life. Another staff thought that sometimes it was hard to cope with challenges in workplace, which created extra pressure, particularly "reduces speed and quality of work." Staff told sometimes they got angry in office, however, nobody agreed that they lost their control fully. Generally, they kept quiet and took a break it helped them to understand the situation. It also helped to think about the cause of anger and find the way to get rid of it. However, they agreed anger hampered their 
work flow, created trouble in relationships with colleagues, and caused some health problems like headache and anxiety. Furthermore, BRAC employees were less satisfied about their performance; they will not assess it favourably unless other colleagues praise it. That may well mean that their job satisfaction depends on how others (particularly supervisors) assess their work. If the supervisor shows trust and belief on their staff and their capabilities, then the staff's confidence level increases automatically. Hence, staff can gain a sense of self-efficiency if their manager guides them properly and deals with cases of low self-esteem carefully.

\section{Regulating Emotions}

More than half of the employees were worried, less able to reduce tension, and less willing to keep promise (Table 3). Nearly $40 \%$ of the employees had less adaptability and innovativeness. Even though nearly $90 \%$ of the employees liked to stick to their work plan, almost half of them reported that they could change their approach depending on the situation. Further, nearly $70 \%$ reportedly sought new ideas, although only $40 \%$ of them felt that there was plausibility to use them. However, as employees reported, there is little scope for implementing new ideas or initiatives.

In group discussion employees showed worried and tensed about making mistakes. In order to tackle this kind of negative emotion effectively, "there needs to be a complete guideline for doing any work, and it is essential to make a network of sharing" - as one respondent opined. Several of them emphasized on doing work systematically and sharing with supervisors and colleagues. It is helpful to reduce tension and keep on the right track. Adaptability is a valuable character trait which helps those who possess it to be flexible with their work and across a wide range of situations.

Table 2. Opinions on awareness on individual emotions

\begin{tabular}{|c|c|c|c|c|c|}
\hline Statement & $\begin{array}{c}\text { Strongly } \\
\text { agree }\end{array}$ & Agree & Neutral & Disagree & $\begin{array}{c}\text { Strongly } \\
\text { disagree }\end{array}$ \\
\hline I find myself feeling nervous about new situations & 2.9 & 12.9 & 15.9 & 47.6 & 20.6 \\
\hline When I get angry I can't stop myself easily & 5.2 & 16.8 & 15.0 & 42.8 & 20.2 \\
\hline When I get stressed I can't give quality output & 14.2 & 26.1 & 13.1 & 35.2 & 11.4 \\
\hline I know exactly where I want to be in five years & 30.6 & 41.4 & 20.4 & 6.4 & 1.3 \\
\hline It is difficult for me to identify my weaknesses & 5.1 & 6.9 & 5.7 & 58.9 & 23.4 \\
\hline I like to use my experience before decisions making & 38.9 & 55.4 & 4.6 & 1.1 & - \\
\hline I have been learning new things from every feedback & 41.0 & 50.3 & 7.5 & 1.2 & - \\
\hline Sometimes I share funny things with my colleagues & 40.2 & 52.9 & 5.2 & 1.7 & - \\
\hline I am not satisfied with my work unless someone else praises it & 8.5 & 19.9 & 22.2 & 37.5 & 11.9 \\
\hline I don't hesitate to express the truth & 54.3 & 36.0 & 5.7 & 2.9 & 1.1 \\
\hline
\end{tabular}

Table 3. Item-wise proportion of opinion on regulating emotions

\begin{tabular}{|c|c|c|c|c|c|}
\hline Statement & Strongly agree & Agree & Neutral & Disagree & Strongly disagree \\
\hline When I get tensed I cannot reduce it easily & 15.4 & 36.0 & 13.7 & 29.1 & 5.7 \\
\hline It is hard for me to focus under pressure & 3.6 & 15.5 & 14.9 & 47.6 & 18.5 \\
\hline I worried about the consequences of my work & 15.2 & 40.4 & 15.8 & 22.8 & 5.8 \\
\hline I cannot take facilities that I do not deserve & 64.1 & 31.2 & 4.1 & 0.6 & - \\
\hline My colleagues think that I am a reliable person & 44.8 & 47.3 & 7.3 & 0.6 & - \\
\hline I always say sorry for my mistakes & 55.5 & 39.3 & 4.6 & - & 0.6 \\
\hline It is difficult to keep all promises & 18.3 & 39.1 & 18.9 & 18.9 & 4.7 \\
\hline I am completely concerned about my responsibilities & 65.3 & 32.4 & 1.1 & 0.6 & 0.6 \\
\hline Sometimes I feel stressed if things change quickly & 7.7 & 36.1 & 20.1 & 29.6 & 6.5 \\
\hline Situation wise I can change my approach & 9.8 & 38.4 & 23.2 & 22.0 & 6.7 \\
\hline I am seeking for new ideas & 18.7 & 51.2 & 20.5 & 9.6 & - \\
\hline I have little scope to use new ideas & 13.7 & 27.4 & 17.7 & 34.3 & 6.9 \\
\hline I do my work according to my work plan & 38.7 & 50.9 & 7.5 & 2.9 & \\
\hline
\end{tabular}




\section{Self-motivation}

BRAC employees were found much motivated about improving their performance, taking challenging task, less demanding on leave, aware of division's goals and valuing the group's opinion (Table 4). However, nearly one-third of the employees had fear of failure rather than hope for success. Therefore, it can be said that a significant amount of BRAC staff are less optimistic about success.

A participant mentioned that when creating a team his supervisor was always aware of putting a less skilled employee with a more skilled employee. Hence, the employees can improve their work standards by sharing experiences and modelling their performance on other, more skilled colleagues. The employees agreed that if they constantly worry about their task, they will achieve less. However, every person has different motivations for working. As reported, more work but less payment can affect inspiration negatively. Moreover, it also appeared that monotonous work can also hamper the drive for achievement, which is somewhat contradictory to the finding that BRAC employees tend to feel stressed when confronted with new tasks and situations (Table 2).

\section{Socially Aware}

It appears that over $90 \%$ of BRAC employees have the capacity to recognize others' feelings and try to understand others' happy or sad incidents in life. Similarly, 97.1\% of the employees tried to help others if they needed (Table 5). Few people (4\%) rarely acknowledge and reward people's strengths and contributions. Perhaps more importantly, approximately $46 \%$ employees were found dissatisfied with their staff assessment process. They thought it did not offer useful feedback and did not identify the needs for development properly. Nearly $90 \%$ of the employees were found to be open for guiding others.

Staffs also try to show sensitivity and help others when they struggle with their task. They also agreed that they got same attention and help from their team mates when they need help and kindness. Moreover, the employees also agreed that in making sense of a person's dignity, or adaptation, the common cultural background makes a person culturally aware. Nowadays, BRAC programmes expand in other countries so it is required to understand diverse worldviews and show sensitivity to different groups of people. An opposite scenario was found from the female staff. Female employees reported that they got less recognition for their work and their male supervisor is less keen to open up with them. That it creates a distance and hampers their learning. During pregnancy and lactating period, they want sympathy from their colleagues, because on that time they were having some physical and mental changes. Sometime they didn't get the support as they want.

One issue is prominent from discussion; staff is not satisfied with the existing performance assessment procedure. Several employees believed that a reverse appraisal system should be introduced for the supervisors. This appraisal system would rate the supervisors on such attributes as leadership skills, honesty, transparency, accountability, gender sensitivity and sympathy. Should this appraisal system be introduced, the rating would be done by subordinates. The logic behind that is, if subordinates need to show empathy then the supervisor needs to show empathy as well. And maybe they would need training in this regard.

Table 4. Item-wise proportion of opinion on self-motivation

\begin{tabular}{|c|c|c|c|c|c|}
\hline Statement & Strongly agree & Agree & Neutral & Disagree & Strongly disagree \\
\hline I do not like challenging tasks because it is risky & 0.6 & 2.9 & 8.1 & 52.6 & 35.8 \\
\hline I always try to learn from others for improvement & 61.7 & 36.6 & 1.1 & 0.6 & - \\
\hline When I feel that I can't succeed then I look for alternatives & 24.7 & 57.2 & 12.0 & 5.4 & 0.6 \\
\hline I do not enjoy leave except for emergency & 71.0 & 26.1 & 1.1 & 1.1 & 0.6 \\
\hline I am aware of the purpose of my programme & 71.0 & 27.3 & 1.1 & - & 0.6 \\
\hline I feel worried not to be successful & 6.9 & 22.5 & 16.2 & 38.2 & 16.2 \\
\hline
\end{tabular}

Table 5. Item-wise proportion of opinion on social awareness

\begin{tabular}{|c|c|c|c|c|c|}
\hline Statement & Strongly agree & Agree & Neutral & Disagree & Strongly disagree \\
\hline If anybody expresses his feelings, I try to pay attention to him & 34.9 & 58.9 & 5.7 & 0.6 & - \\
\hline I sympathize with other's feelings & 63.1 & 35.2 & 1.1 & 0.6 & - \\
\hline If any of my colleagues feels nervous, I usually try to help him & 45.7 & 51.4 & 2.9 & - & - \\
\hline I rarely acknowledge others contributions & 2.9 & 1.7 & 2.3 & 35.6 & 57.5 \\
\hline Staff needs are not properly addressed in assessment system & 18.3 & 27.4 & 21.3 & 25.0 & 7.9 \\
\hline I guide others to enhance their skills & 48.0 & 41.6 & 8.7 & 1.2 & 0.6 \\
\hline I show respect and friendly attitude with opposite sex colleagues & 61.5 & 33.3 & 4.0 & - & 1.1 \\
\hline I can adjust myself with different culture people & 55.4 & 42.3 & 1.7 & 0.6 & - \\
\hline
\end{tabular}




\section{Social Skills}

About $63 \%$ of the employees reported that they could influence others, and $87 \%$ reported that they could adapt their choice of wording according to their audience (Table 6). About $75 \%$ reported that they were always open for debate and nearly $90 \%$ reported that they used to listen attentively to their colleagues' ideas and suggestions. This can only mean a fine degree of cooperation among BRAC staff. However, nearly $20 \%$ reported that they tend to ignore issues that may bring disagreement; while it appears that more employees are confident of handling co-employees diplomatically. Almost every staff member agreed that colleagues should respect and help each other and encourage active participation within a team.

From detail discussion it was discovered that most of the staff preferred to stay in comfort zone. They thought both groups needed time to rethink about their logics. Several staff members said that they tend to express their opinion, but then left it with their supervisors to handle. Some employees agreed that there is less scope for discussion in office. Two main reasons have been cited for this: one, they suppose that they are less welcome and two, nobody wants to start clash with others.

\section{Job Satisfaction}

Table 7 represents 10 just over one-fourth of the staff reported that they got sufficient appreciation of their good work. Additionally, $85.5 \%$ staff agreed they felt pride for working with BRAC. Likewise, staff appeared dissatisfied in-terms of payment and job security. Regarding supervision, nearly one-fourth of the staff stated that they faced difficulty in satisfying their supervisors. Nearly $70 \%$ of the staff agreed that their supervisors had the knowledge of how to make their subordinates more efficient.

Table 6. Item-wise proportion of opinion on social skills

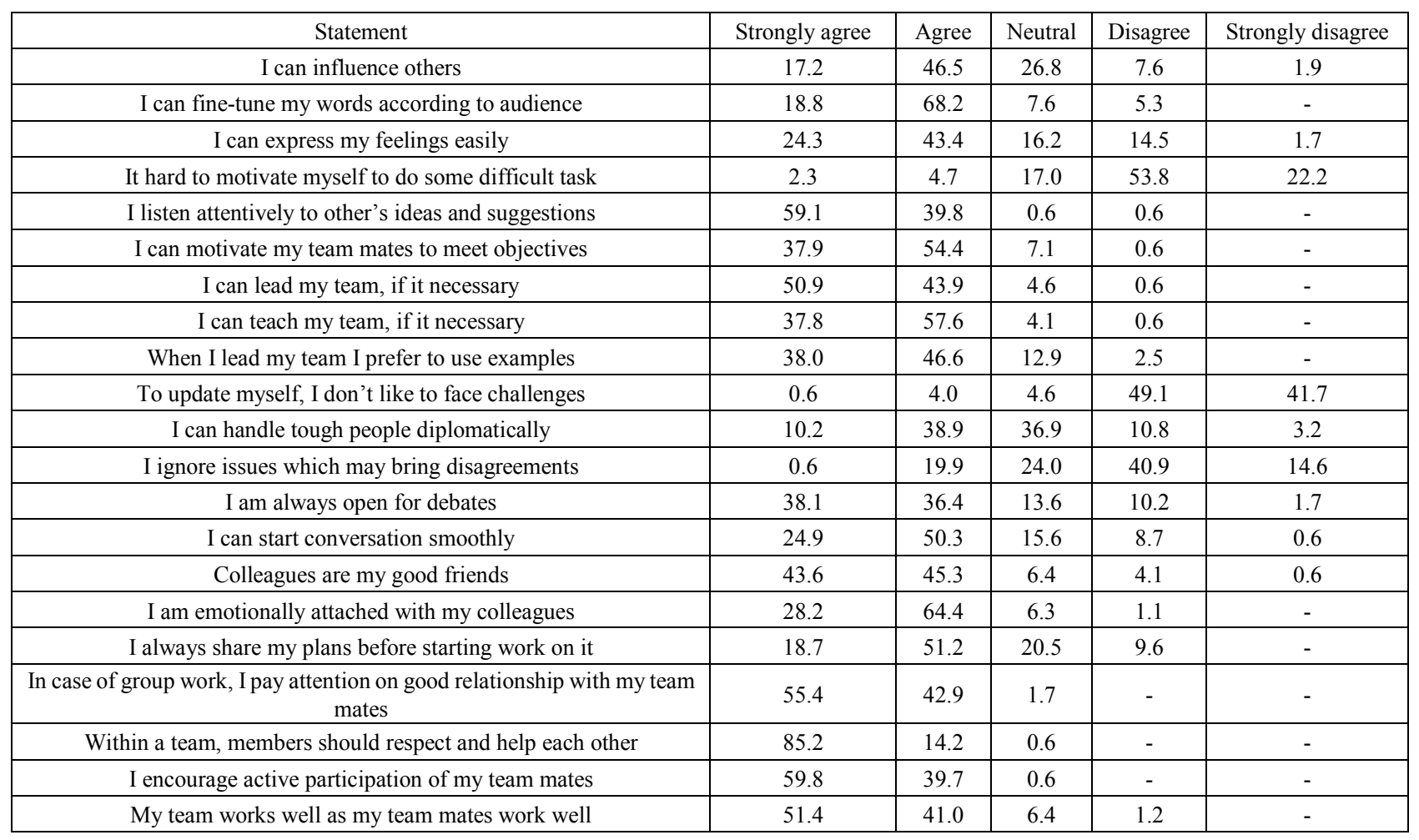

Table 7. Item-wise proportion of opinion on job satisfaction

\begin{tabular}{|c|c|c|c|c|c|}
\hline Statement & Strongly agree & Agree & Neutral & Disagree & Strongly disagree \\
\hline I have received adequate recognition for my good performance & 10.3 & 30.9 & 22.3 & 26.9 & 9.7 \\
\hline I feel pride when I say I work for BRAC & 51.4 & 34.1 & 12.1 & 1.7 & 0.6 \\
\hline The remuneration is less than I deserve & 35.3 & 31.2 & 21.8 & 9.4 & 2.4 \\
\hline I feel my position is secure in this office & 33.7 & 33.7 & 14.0 & 13.4 & 5.2 \\
\hline It is very hard to please my supervisor & 9.9 & 14.5 & 22.1 & 39.0 & 14.5 \\
\hline My supervisor lets me know how I can do well & 24.0 & 45.1 & 12.6 & 13.7 & 4.6 \\
\hline I trust my colleagues & 34.3 & 49.7 & 12.0 & 3.4 & 0.6 \\
\hline It is rare to get support from my colleagues & 2.3 & 5.8 & 13.9 & 62.4 & 15.6 \\
\hline The opportunity of getting a promotion here is limited & 19.5 & 32.5 & 16.6 & 26.0 & 5.3 \\
\hline This organization has unfair promotion policy & 12.2 & 21.3 & 30.5 & 28.7 & \\
\hline
\end{tabular}


In case of co-worker BRAC personnel seem quite lucky, almost $80 \%$ of them reported that they had faith and they got co-operation from their colleagues. Lastly, around half of the staff thought that there was inadequate promotion in BRAC and more than $30 \%$ deemed that BRAC has unfair promotion policy as well. However, they felt a bit discomfort when they reconcile the way to satisfy their manager, salary and promotion policy.

\section{Comparing Mean Score between Sub Scales}

A remarkable similarity found between male and female employees' mean scores on SEI aspects in figure 1. Even though male personnel scored higher in every aspect of SEI (only scores of self-awareness are similar), there is virtual parity on the fluctuation of mean scores.

\section{Percentage of Mean}

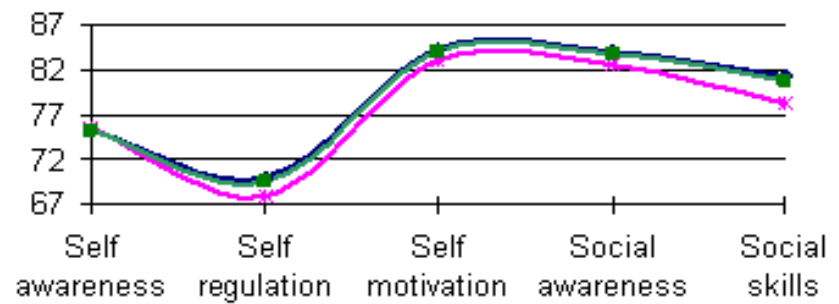

$$
\multimap \text { Male } \ldots \text { Female } \because \text { Both }
$$

Figure 1. Sex-wise mean comparison between five sub-scales

Specifically, both male and female employees showed the same level of self-awareness; they both score remarkably low in regulating their emotion, whereas both scored highest on self-motivation. And these five means were significantly differ within this two group. In conclusion, there is gender equality on Social and Emotional Intelligence among BRAC staff. Thus, the profile of the BRAC employee is someone who knows his emotions, highly motivated in reaching the set goals, cooperates effectively with colleagues, yet felt a bit difficulty to cope with stress and lack of confidence at times.

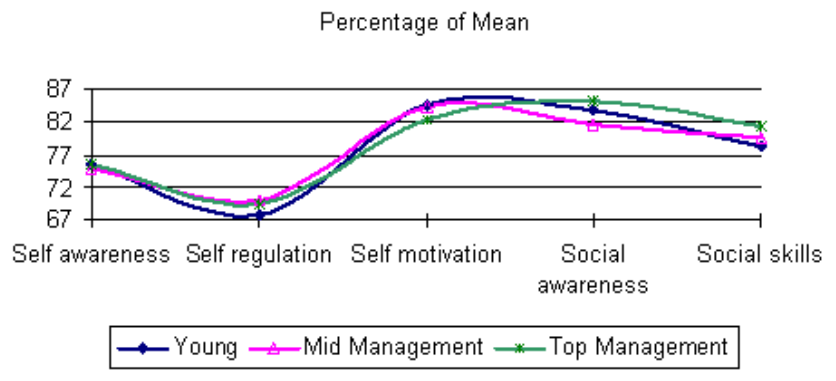

Figure 2. Job level-wise means comparison between five subscales
The findings show level-wise parity regarding the aspects of SEI among BRAC employees; all levels show similar fluctuation in mean scores (Fig. 2), i.e. all scores have high and low at the same segments of SEI. Findings also show that the young group was less able to control their own emotion. Young employees felt somewhat uneasy in coping with daily stresses and job challenges. The other two groups (mid and upper management) scored noticeably higher on this aspect.

Young group found the most self-motivated comparing with other employees. Perhaps motivation decreased over time. Top management scored higher than the rest on social awareness and social skills, perhaps indicative of their willingness to help their younger colleagues develop and achieve their potential within BRAC. Finally, it comes as no surprise that the more experienced BRAC staff possess the higher degree of social skills, with the fresh employees still learning their conduct.

\section{SEI Score Predictor}

For estimating SEI score here we put strongly disagree $=1$, disagree $=2$, neutral $=3$, agree $=4$, and strongly agree $=5$. In case of negative statement, this score was reversed. By summarized all the scores we got the SEI scores and to know which factors influence the SEI a multiple regression analysis was done where job level, JS, length of service at $\mathrm{BRAC}$, and age of the employees were defined as predictors and the SEI score defined as the dependent one.

Table 8. Regression analysis model summary

\begin{tabular}{|c|c|c|c|c|c|}
\hline \multicolumn{5}{|c|}{ Model Summary } & \\
\hline $\mathrm{R}$ & $\mathrm{R}^{2}$ & Adjusted $\mathrm{R}^{2}$ & $\begin{array}{c}\text { Std. Error of } \\
\text { the Estimate }\end{array}$ & $\mathrm{F}$ & Sig. \\
\hline 0.431 & 0.186 & 0.166 & 20.73 & & \\
\hline \multicolumn{3}{|c|}{$\begin{array}{l}\text { Predictors: (Constant) Job level, Job satisfaction, } \\
\text { Experience, Age }\end{array}$} & 9.569 & $.000^{\mathrm{a}}$ \\
\hline
\end{tabular}

The regression analysis presents a slightly weak $\left(\mathrm{R}^{2}\right.$ $=0.186)$ but statistically significant $(\mathrm{F}=9.569$, Sig. $=0.00)$ prediction (Tables 8 ). The value of $\mathrm{R}^{2}$ indicates employees' age, experience, job level and job satisfaction can explain $18.6 \%$ of their SEI. Without any influence of any predictor, staff can get approximately 181 out of 295 . The value Variance Inflation Factor (VIF) indicates that the assumption no multi-collinearity was met (Table 9). This analysis reveals that the predictor set significantly predicts the outcomes. Among the set of predictors age and experience of employees seem to be weak predictors, whereas job level and its satisfaction were the stronger predictors. Job level, was by far the strongest predictor. 
Other two independent variables experience and age $\left(\beta_{\text {experience }}=-0.595, \mathrm{~ns}\right)$ and $\left(\beta_{\text {age }}=0.171, \mathrm{~ns}\right)$ are relatively weak predictors. Yet, these values of $\beta$ indicate that older employees and those had less experience are somewhat more likely to hold that the level of SEI. Table 9 shows that VIF values for age and job experience are higher than 1 . However, that was expected, since the most experienced employees are likely to be the older ones, and the older ones are more likely to have developed their SEI.

\section{Is SEI Score Can Explain Job Satisfaction?}

To examine whether JS is influenced by SEI components, another multiple regression was done where the five SEI components were defined as predictors and the JS defined as the dependent variable. This regression analysis reveals the predictor set significantly predicts the outcome $(\mathrm{F}=7.068$, Sig. $=0.00$ ) prediction (Tables 10 ), and SEI components explain $25 \%$ of JS $\left(\mathrm{R}^{2}=0.256\right)$.

Age and job level appear to be the weakest predictors, whereas social awareness and self-regulation the strongest in this set. Social awareness was the most important determinant of job satisfaction. Therefore, it can be said that the ability to take into account other people's feelings and perspectives, paying attention to colleagues' emotional needs, the ability to form relationships with colleagues and show understanding towards them greatly determines job satisfaction.

Table 9. Regression coefficients

\begin{tabular}{|c|c|c|c|c|c|c|c|c|c|}
\hline \multicolumn{10}{|c|}{ Coefficients $^{\mathrm{a}}$} \\
\hline \multirow{2}{*}{ Model } & \multicolumn{2}{|c|}{$\begin{array}{l}\text { Unstandardized } \\
\text { Coefficients }\end{array}$} & \multirow{2}{*}{$\begin{array}{c}\begin{array}{c}\text { Standardized } \\
\text { Coefficients }\end{array} \\
\text { Beta }\end{array}$} & \multirow{2}{*}{$\mathrm{T}$} & \multirow{2}{*}{ Sig. } & \multicolumn{2}{|c|}{$\begin{array}{l}95.0 \% \text { Confidence } \\
\text { Interval for B }\end{array}$} & \multicolumn{2}{|c|}{ Collinearity Statistics } \\
\hline & $\mathrm{B}$ & Std. Error & & & & $\begin{array}{l}\text { Lower } \\
\text { Bound }\end{array}$ & $\begin{array}{l}\text { Upper } \\
\text { Bound }\end{array}$ & Tolerance & VIF \\
\hline (Constant) & 180.72 & 12.88 & & 14.03 & .00 & 155.29 & 206.14 & & \\
\hline JS & 1.38 & .23 & .44 & 6.05 & .00 & .93 & 1.83 & .93 & 1.07 \\
\hline Job level & 1.61 & 2.16 & .06 & .75 & .46 & -2.66 & 5.87 & .81 & 1.24 \\
\hline Experience & -.59 & .39 & -.23 & -1.54 & .13 & -1.36 & .17 & .21 & 4.76 \\
\hline Age & .17 & .38 & .07 & .45 & .66 & -.59 & .93 & .20 & 4.98 \\
\hline \multicolumn{10}{|c|}{ a. Dependent Variable: SEI score } \\
\hline
\end{tabular}

Table 10. Regression analysis model summary

\begin{tabular}{|c|c|c|c|c|c|}
\hline \multicolumn{2}{|c|}{ Model Summary } & & \\
\hline $\mathrm{R}$ & $\mathrm{R}^{2}$ & Adjusted $\mathrm{R}^{2}$ & Std. Error of the Estimate & $\mathrm{F}$ & Sig. \\
\hline $.506^{\mathrm{a}}$ & .256 & .220 & 6.35 & & \\
\end{tabular}

Table 11. Regression coefficients

\begin{tabular}{|c|c|c|c|c|c|c|c|c|c|}
\hline \multicolumn{10}{|c|}{ Coefficients $^{\mathrm{a}}$} \\
\hline \multirow{2}{*}{ Model } & \multicolumn{2}{|c|}{$\begin{array}{l}\text { Unstandardized } \\
\text { Coefficients }\end{array}$} & \multirow{2}{*}{$\begin{array}{c}\begin{array}{c}\text { Standardized } \\
\text { Coefficients }\end{array} \\
\text { Beta }\end{array}$} & \multirow{2}{*}{$\mathrm{t}$} & \multirow{2}{*}{ Sig. } & \multicolumn{2}{|c|}{$\begin{array}{l}95.0 \% \text { Confidence } \\
\text { Interval for B }\end{array}$} & \multicolumn{2}{|c|}{ Collinearity Statistics } \\
\hline & $\mathrm{B}$ & $\begin{array}{l}\text { Std. } \\
\text { Error }\end{array}$ & & & & $\begin{array}{l}\text { Lower } \\
\text { Bound }\end{array}$ & $\begin{array}{l}\text { Upper } \\
\text { Bound }\end{array}$ & Tolerance & VIF \\
\hline (Constant) & -2.09 & 6.19 & & -.34 & .74 & -14.33 & 10.13 & & \\
\hline Self-awareness & .09 & .13 & .06 & .69 & .49 & -.17 & .35 & .56 & 1.78 \\
\hline Self-regulation & .20 & .13 & .15 & 1.56 & .12 & -.05 & .46 & .52 & 1.92 \\
\hline Self-motivation & .08 & .22 & .04 & .36 & .72 & -.35 & .51 & .48 & 2.09 \\
\hline Social awareness & .48 & .17 & .25 & 2.81 & .01 & .14 & .81 & .59 & 1.70 \\
\hline Social skills & .04 & .07 & .06 & .57 & .57 & -.09 & .17 & .45 & 2.24 \\
\hline Age & -.04 & .12 & -.05 & -.29 & .77 & -.27 & .20 & .19 & 5.17 \\
\hline Job level & .09 & .68 & .01 & .14 & .89 & -1.24 & 1.44 & .77 & 1.3 \\
\hline Experience & .28 & .12 & .28 & 1.89 & .06 & -.01 & .46 & .21 & 4.81 \\
\hline
\end{tabular}


However, such statement should be treated cautiously. As pointed out earlier, it can be a two-way relationship between JS and SEI components. Forming constructive relationships with colleagues can definitely enhance job satisfaction. JS itself can encourage people to interact with their colleagues in a more friendly and constructive manner: if someone is happy with his job, chances are that he or she would happily interact with colleagues and show understanding towards their needs. Nevertheless, the fact that the SEI set of components explain $25 \%$ of JS signifies that social and emotional skills are an important aspect in job satisfaction and, consequently, a more productive working environment.

\section{Discussion}

A mixed picture was found where positive signs are BRAC employees are able to understand their own emotion and cooperative with their team mates. They have a sense of self-worth which helped them to effectively deal with their responsibilities and challenges. However, the negative emotions affect their beliefs and performances. Staff knew their emotions and ability to link between them, but they were found less able to control it. Hence, stress, tension and worry affect employees and it is a potential barrier in providing quality performance. Furthermore, anger ruins staff's own image and interpersonal relationship. They were less aware about their strengths/weaknesses, fear to face new challenge, less able to influence others and express own emotions. These indicate lack of self-assurance. They liked to stay in comfort zone and avoided disagreement. Some of them were found less open for debate and had a tendency to accept all decisions whether right or wrong. Relationship with supervisor was frequently hampered due to poor communication and personal bias.

Generally women are more emotionally expressive than men. Evidence found that women's brain contributes of processing emotions more than their counterpart [11] and they are more capable in regulating it [12]. Female staff also has more responsibility in their family matters and they usually bring more anxiety from home. So for female staff it is essential to understand how she can be able to make an emotional balance in family and at office.

Therefore, three reasons are identified for improving SEI. Firstly, an employee might want to increase his effectiveness at work or increase his/her chances for promotion. Secondly, the incentive may be more personal, that is a person may simply want to better himself. A third possibility would be altruistic; in that a person might want to help others develop emotional intelligence to pursue their goals.

\section{Conclusions}

For enhancing SEI, firstly it should in mind that usually people learn these issues from their family. In workplace everybody is quite mature and they already have a set of beliefs, perceptions and practice of emotions. Every individual has different psychological features and job nature and colleagues. So, trainers need to be conscious on the aim of this training. On the other hand, trainers also adopt the SE skills and promoting it otherwise employees will not feel the importance of it. In promoting self-motivations, different psychological and psychotherapeutic techniques have been employed, which sets to activate an individual's 'achievement drive' through various intellectual exercises. Social skills are promoted mainly by behavioral modeling i.e. observing someone else successfully carrying out a task or handling a socially demanding situation, the idea being that the observer will model his behavior on what he observes. Such training programmes have been delivered to employees at all levels, directors, executives and subordinates. Staff talked about the techniques, trainers should have established some problem solving techniques which can help boost SE skills.

\section{Acknowledgements}

We are grateful to Dr. Elizabeth Spier of American Institute of Research for her continuous attention and feedback for the study.

\section{REFERENCES}

[1] Goleman D. Working with Emotional Intelligence in Workplace, Jossey-Bass; United States of America, 1998.

[2] Gardner H. Frames of Mind: The Theory of Multiple Intelligences. Basic Books; United States of America, 1983.

[3] Goleman D. Emotional Intelligence: Why It Can Matter More Than IQ for Character, Health and Lifelong Achievement, Bantam Books; United States of America, 1995.

[4] Mayer J, Salovey P, Caruso D. Competing models of emotional intelligence Handbook of Human Intelligence, Cambridge University Press; United Kingdom, 2000.

[5] Mount G, editor. Linking Emotional Intelligence And Performance At work: Current Research Evidence With Individuals and Groups. Lawrence Erlbaum Associates; United States of America, 2005.

[6] Thorndike ER. A constant error in psychological ratings. Journal of Applied Psychology, 1920: 4(1):25-29.

[7] Bar-On R. The Bar-On emotional quotient inventory (EQ-i): A Test of Emotional Intelligence. Multi Health Systems; Canada, 1997.

[8] Bar-On R. The impact of emotional intelligence on subjective. Perspectives in Education, 2005: 23(2):41-61.

[9] Cherniss C, Goleman D. The Emotionally Intelligent Workplace: How to Select For, Measure, and Improve Emotional Intelligence in Individuals, Groups, and 
Organizations, Jossey-Bass; United States of America, 2001.

[10] Smith, PC, Kendall L.M, and Hulin C.L. The Measurement of Satisfaction in Work and Retirement. Rand McNally; United States of America, 1969.
[11] Baron-Cohen S. The essential difference: Men, women and the extreme male brain, Allen Lane; United Kingdom, 2003.

[12] Bindu P \& Thomas T. Gender Difference in Emotional Intelligence: Psychocological Studies, 2006; 51(4):261-68. 